\title{
New insights in the global cycle of acetonitrile: release from the ocean and dry deposition in the tropical savanna of Venezuela
}

\author{
E. Sanhueza ${ }^{1,2}$, R. Holzinger ${ }^{1, *}$, B. Kleiss ${ }^{1}$, L. Donoso ${ }^{2}$, and P. J. Crutzen ${ }^{1}$ \\ ${ }^{1}$ MPI für Chemie, Luftchemie, Postfach 3060, 55020 Mainz, Germany \\ ${ }^{2}$ IVIC, Atmospheric Chemistry Laboratory, Apartado 21827, Caracas 1020A, Venezuela \\ *now at Univ. Calif. Berkeley, Div Environm Sci, Dept. Ecosyst. Sci. Policy \& Management, Berkeley, CA 94720, USA
}

Received: 19 September 2003 - Published in Atmos. Chem. Phys. Discuss.: 20 October 2003

Revised: 23 January 2004 - Accepted: 2 February 2004 - Published: 9 February 2004

\begin{abstract}
Using the proton transfer reaction mass spectrometry (PTR-MS) technique, acetonitrile was measured during the wet season in a Venezuelan woodland savanna. The site was located downwind of the Caribbean Sea and no biomass burning events were observed in the region. High boundary layer concentrations of $211 \pm 36 \mathrm{pmol} / \mathrm{mol}$ (median, \pm standard deviation) were observed during daytime in the well mixed boundary layer, which is about $60 \mathrm{pmol} / \mathrm{mol}$ above background concentrations recently measured over the Mediterranean Sea and the Pacific Ocean. Most likely acetonitrile is released from the warm waters of the Caribbean Sea thereby enhancing mixing ratios over Venezuela. Acetonitrile concentrations will probably still be much higher in biomass burning plumes, however, the general suitability of acetonitrile as a biomass burning marker should be treated with care.

During nights, acetonitrile dropped to levels typically around $120 \mathrm{pmol} / \mathrm{mol}$, which is consistent with a dry deposition velocity of $\sim 0.14 \mathrm{~cm} / \mathrm{s}$ when a nocturnal boundary layer height of $100 \mathrm{~m}$ is assumed.
\end{abstract}

\section{Introduction}

Acetonitrile (methyl cyanide, $\mathrm{CH}_{3} \mathrm{CN}$ ) is an ubiquitous trace gas in the atmosphere. Chemically relatively stable it reaches the stratosphere and is one of the ligands of positive stratopheric cluster ions (e.g. Arnold et al., 1978). Biomass burning has been identified to be by far the dominant source of acetonitrile and has therefore been proposed as a tracer for biomass burning emissions (Lobert et al., 1990; Holzinger et al., 1999). However, the atmospheric budget of acetonitrile is poorly understood. The estimated lifetime ranges from 0.45 (Hamm and Warneck, 1990) to 1.5 years (Hamm et al.,

Correspondence to: R. Holzinger

(holzing@ nature.berkeley.edu)
1984); wet deposition and reaction with HO radicals lead to the longer lifetime, whereas accounting for a potentially strong oceanic sink produces short lifetimes of 5.4 (Hamm and Warneck, 1990) and 6.8 months (Singh et al., 2003). Recently, some papers reported oceanic uptake of acetonitrile (Karl et al., 2003; Warneke and de Gouw, 2001; Singh et al., 2003; Jost et al., 2003; de Gouw et al., 2003) thereby emphasizing a shorter atmospheric lifetime of acetonitrile. The oceanic sink is estimated to be larger than or of the same order as chemical degradation via reaction with the $\mathrm{HO}$ radical. With current knowledge it is hard to balance acetonitrile's global budget - even if the highest estimates of biomass burning emission are considered, the assumed sinks are larger. Consequently, there has been much speculation about additional major sources. However, there is little evidence for such additional sources. In this paper we present a dataset of PTR-MS measurements revealing new insights into the global cycle of acetonitrile. Daytime mixing ratios at a Venezuelan savanna site downwind the Caribbean Sea were clearly above background levels thereby giving evidence of $\mathrm{CH}_{3} \mathrm{CN}$ being released from the ocean. In addition dry deposition of acetonitrile into the local savanna ecosystem was observed.

\section{Field site characteristics}

Figure 1 shows the location of the measurement site (Calabozo). In most part of Venezuela the climate is driven by seasonal movements of the equatorial trough (Inter-tropical Convergence Zone). The changing position of the trough influences seasonal rainfall. During winter when the trough is in the Southern Hemisphere, a five-month dry season occurs (December to April), while a seven-month wet season occurs when the trough is over Venezuela (May to November). The distinction between dry and rainy season becomes progressively less marked toward the equator (i.e. latitudes 

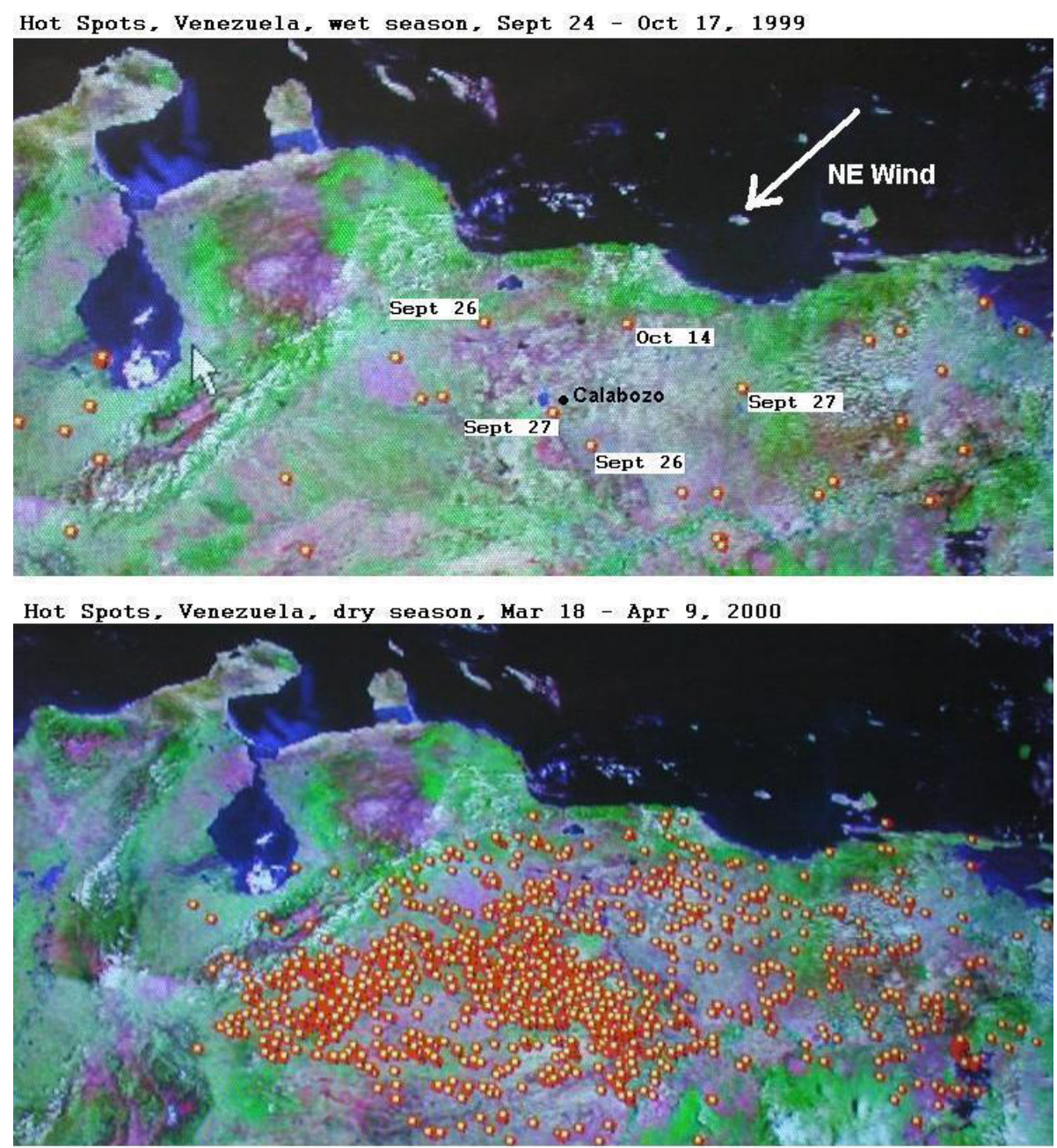

AVHRR data from the NOAH 12 satellite, http://www.dpi.inpe.br/proarco/bdqueimadas/proarco.html

Fig. 1. Map indicating the monitoring site and fires that have been detected with the NOAH 12 satellite; (a) during the period of the wet season measurements (top chart); (b) during dry season measurements performed at the same site in April 2000 (bottom chart). The potential of biomass burning influence is very small in the wet season.

lower than $6^{\circ} \mathrm{N}$ ) where frequent rains also occur during the dry season, whereas in the northern part of the region very marked dry and rainy seasons are observed. A region of trade winds lies between the equatorial trough and the sub-tropical highs. These wind systems are steadiest at the surface and are weaker in the wet season than in the dry season. Northeast to east-northeast trades are the prevailing winds for the area north of $5^{\circ} \mathrm{N}$, indicating that a large amount of surface air reaching the savanna region comes from the ocean, spending less than one day over land.

Continuous measurements were made in the Biological Station of the Plains (Estación Biológica de los Llanos) located nearby Calabozo $\left(8^{\circ} 53^{\prime} \mathrm{N} ; 67^{\circ} 19^{\prime} \mathrm{W}\right)$, during the wet season 24 September to 17 October 1999. The site is located in the central part of Venezuela and is little influenced by urban or industrial pollution sources. No biomass burning was observed during the wet season campaign. The surrounding woodland savanna is covered with graminea grasses (e.g. Trachypogon sp, Axonopus canescens, Hiparrhenia rufa) interrupted by trees and scrubs (e.g. Curatella americana, Boudichia virgilioides, Byrsonima crassifolia). The rainfall at the site shows a 22-year average of $1315 \mathrm{~mm}$. Around $98 \%$ of the rainfall occurs between April and November. The annual mean temperature is $27.6^{\circ} \mathrm{C}$.

\section{Measurement techniques}

Acetonitrile was measured on line by Proton-TransferReaction Mass Spectrometry (PTR-MS) which has been described elsewhere in detail (Lindinger et al., 1998).

The air to be analyzed was led through a $15 \mathrm{~m}$ Teflon tube (PFA, ID $1.6 \mathrm{~mm}$ ), the inlet of which was positioned $5 \mathrm{~m}$ 
above ground. The response time of the gas inlet system was kept below $20 \mathrm{~s}$ by applying an appropriate gas flow through the tube. The instrumental background levels were measured by directing the sample flow through a catalytic converter. The converter consisted of a stainless steel tube filled with Platinum-coated quartz wool (Shimadzu) heated to $350^{\circ} \mathrm{C}$, which efficiently removed the volatile organic compounds (VOCs) from the sample. The catalytic converter did not remove water vapor from the sample, which is important because the background impurities may depend on the humidity of the sampled air. The PTR-MS instrument consists of three parts: ion source, reaction chamber, and a quadrupole mass spectrometer. The primary $\mathrm{H}_{3} \mathrm{O}^{+}$ions enter the reaction chamber which is flushed with the air to be analyzed. On the way to the mass spectrometer each $\mathrm{H}_{3} \mathrm{O}^{+}$ion collides a 1000 times with neutral molecules mostly with non-reactive $\mathrm{N}_{2}, \mathrm{O}_{2}$, Ar, and $\mathrm{CO}_{2}$ molecules. However, a proton will be transferred on almost every collision between a $\mathrm{H}_{3} \mathrm{O}^{+}$ion and a VOC with a proton affinity higher than water. Thus most of the VOC species are detected at their protonated mass which is the molecular mass +1 . The collision energy of the ions with neutral compounds is maintained at a sufficiently high value by the applied electric field (electric field to number density: $\mathrm{E} / \mathrm{N} \approx 130 \mathrm{Td}$; $1 \mathrm{Td}=1$ Townsend $=10^{-17} \mathrm{~V} \mathrm{~cm}^{2}$ ) so that clustering of the hydronium ions with water molecules to form higher hydrates is strongly suppressed. The electric field also controls the transient time $(\mathrm{t})$ for the $\mathrm{H}_{3} \mathrm{O}^{+}$ions traversing the reaction chamber thus allowing to calculate the neutral trace gas density from the relation $\left[\mathrm{VOC} \cdot \mathrm{H}^{+}\right] \approx\left[\mathrm{H}_{3} \mathrm{O}^{+}\right][\mathrm{VOC}] \mathrm{k}_{\text {VOC }} \mathrm{t}$, where $\mathrm{k}_{V O C}$ is the reaction rate constant for the proton transfer from $\mathrm{H}_{3} \mathrm{O}^{+}$to compound VOC.

Acetonitrile is detected at protonated mass 42. Potential interference at this mass might come from compounds which produce ion signals at mass $41\left(\mathrm{C}_{3} \mathrm{H}_{5}^{+}\right.$, e.g. protonated propyne or fragmented isoprene). About $3 \%$ of this non-acetonitrile signal will be detected at mass 42 due to the natural ${ }^{12} \mathrm{C} /{ }^{13} \mathrm{C}$-isotope distribution. The reaction of $\mathrm{O}_{2}^{+}$ (an impurity coming from the ion source) with some alkenes might also produce a signal at mass $42\left(\mathrm{C}_{3} \mathrm{H}_{6}^{+}\right)$. However, we continuously monitored reasonable low levels at masses 32 and 41; thereby excluding considerable interferences of this kind. Studies done with a coupled GC-PTR-MS system demonstrated that the ions associated with acetonitrile are free from significant interference (De Gouw et al., 2003; Warneke et al., 2003).

The accuracy of the data is about $\pm 15 \%$. Gravimetrically mixed standards with acetonitrile levels of 400$1500 \mathrm{nmol} / \mathrm{mol}$ have been measured to confirm correct computation of mixing ratios. The data presented here are highly averaged; that is to say every number presented here is based on good counting statistics for both primary $\mathrm{H}_{3} \mathrm{O}^{+}$ions and protonated acetonitrile. Therefore errors due to precision are considered to be minor $(\sim 5-10 \%)$.

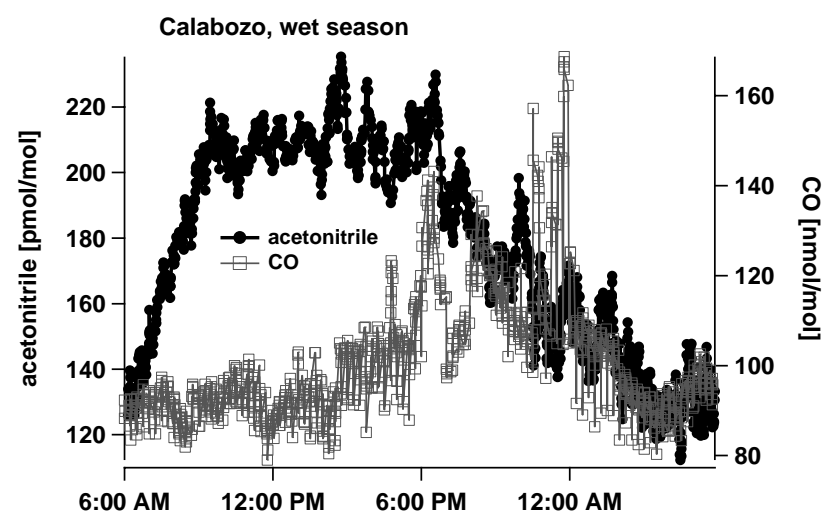

Fig. 2. Diurnal variation of acetonitrile and CO mixing ratios at the Calabozo savanna site. All data collected between 24 September and 17 October 1999 have been superimposed and smoothed by the formation of a running mean out of 15 neighboring points.

Carbon monoxide concentrations were measured using a reduction-gas-detector (Trace Analytical) in combination with a molecular sieve 5A column for CO separation. Every 15 min gas samples were automatically supplied to the injection valve by a Metal Bellow pump (model MB-21). Highpressure mixtures of $\mathrm{CO}$ in synthetic air $(258 \mathrm{ppbv})$ were used for calibration in the field.

\section{Results and discussion}

The top chart of Fig. 1 depicts fire pixels observed by the NOAA 12 satellite during the period of acetonitrile measurements. Less than 10 fires have been detected which potentially could have influenced the site. For comparison, we also present fire pixels detected during the dry season measurement campaign at the same site in April 2000 (bottom chart of Fig. 1). Several hundred fires were detected which clearly influenced the site (see Table 1 for daytime average mixing ratios of acetonitrile). The instrumentation of the NOAA 12 satellite is sensitive enough to detect fire fronts of $30 \mathrm{~m}$ length, as narrow as $0.5 \mathrm{~m}$. So, if at all there was biomass burning influence during the wet season it must have been very minor.

Figure 2 depicts a diurnal cycle of $\mathrm{CH}_{3} \mathrm{CN}$ and $\mathrm{CO}$ into which all data have been included that were obtained during the three weeks of measurement. For both acetonitrile and $\mathrm{CO}$ a significant diurnal variation was observed. Acetonitrile levels continuously decreased during night when vertical mixing was suppressed by the nocturnal inversion layer. The breaking of the nocturnal inversion each morning coincided with a rapid increase of acetonitrile concentrations due to mixing with the residual layer. Daytime mixing ratios between 1100 and 16:00 local time (LT, UTC less $5 \mathrm{~h}$ ) are considered representative for boundary layer concentrations. Decreasing levels of acetonitrile during night can only be 
Table 1. Atmospheric mixing ratios of $\mathrm{CH}_{3} \mathrm{CN}$ (pmol/mol) at various locations.

\begin{tabular}{|c|c|c|c|}
\hline Locations & Average \pm SD & Median & Range \\
\hline Calabozo, wet season, Venezuela ${ }^{a}$ & $212 \pm 36$ & 211 & $159-272$ \\
\hline Calabozo, dry season, Venezuela ${ }^{a}$ & $245 \pm 69$ & 226 & $158-387$ \\
\hline La Gran Sabana region, Venezuela ${ }^{b}$ & $150 \pm 70$ & 140 & \\
\hline Tropical rainforest, Surinam, $0-1 \mathrm{~km}^{c}$ & $189 \pm 76$ & 176 & $108-362$ \\
\hline Tropical Indian Ocean, boundary layer & & & \\
\hline and free troposphere ${ }^{d}$ & & & $70-200$ \\
\hline Mauna Loa Baseline Station, Hawaii ${ }^{e}$ & & & $70-200$ \\
\hline Northwest Indian Ocean, boundary layer $f$ & $142 \pm 20$ & & \\
\hline Pacific Troposphere, $0-12 \mathrm{~km}^{g}$ & $149 \pm 56$ & 138 & $93-205$ \\
\hline Mediterranean Troposphere, $0-13 \mathrm{~km}^{h}$ & 156 & 150 & $123-200$ \\
\hline \multicolumn{4}{|l|}{${ }^{a}$ This Work } \\
\hline \multicolumn{4}{|l|}{$b_{\text {(Sanhueza et al., 2001) }}$} \\
\hline \multicolumn{4}{|l|}{${ }^{c}$ LBA-CLAIRE database } \\
\hline \multicolumn{4}{|l|}{$d_{\text {(Sprung et al., 2001) }}$} \\
\hline \multicolumn{4}{|l|}{${ }^{e}($ Karl et al., 2003) } \\
\hline \multicolumn{4}{|l|}{$f_{\text {(Warneke and de Gouw, 2001) }}$} \\
\hline \multicolumn{4}{|l|}{$g$ (Singh et al., 2003) } \\
\hline$h_{\text {(Holzinger et al., 2003) }}$ & & & \\
\hline
\end{tabular}

explained by dry deposition; poor reactivity and low variability exclude chemistry and advection from being a reasonable explanation of the observed night time losses of acetonitrile. In contrast, $\mathrm{CO}$ is not deposited but measured at highest levels late in the evening. During night the steady Northeasterly wind flow collapsed occasionally and local traffic emissions were advected from nearby Calabozo, a town with a population of about 100000 people. Plumes of anthropogenic tracers like $\mathrm{CO}$, benzene and toluene have been detected occasionally (Holzinger et al., 2001). However, no plumes of acetonitrile have been observed; a fact which also becomes manifested in almost equal levels of the average $(212 \mathrm{pmol} / \mathrm{mol})$ and the median $(211 \mathrm{pmol} / \mathrm{mol})$ mixing ratio. The lack of correlation between acetonitrile and $\mathrm{CO}$ is indicative of the absence of a common source; especially small scale biomass burning like cooking fires or agricultural waste burning. We assume that the region around Calabozo is typical for the Venezuelan plains and so we conclude that small scale fires do not play a significant role in acetonitrile mixing ratios. Venezuela is a petroleum producing country, so this fuel is predominantly used in contrast to many other tropical countries.

In Table 1 reported mixing ratios of acetonitrile are compared with boundary layer levels (11:00-16:00 local time) measured in this study. The concentrations of acetonitrile were clearly above levels measured in other regions with little biomass burning contamination. Surprisingly, the median mixing ratio is not very different from that measured during the dry season with a lot of influence from biomass burning (see Table 1); the latter of which is in good agreement with a 3D modelling exercise recently done by Li et al. (2003).
We figured out following three possible explanations for the high concentrations: i) a regional land-surface source; ii) long-range transport of biomass burning emissions; and iii) a marine source. A land-surface related source must be homogeneously distributed all the way upwind of the site. Otherwise the variability of acetonitrile would have been much larger and plumes would have been detected. Potentially emissions from the vegetation or from the soil could be such a source. However, emissions from both vegetation and soil would be triggered by temperature and/or light variations. For this reason both would result in a different diurnal cycle than observed. Like for isoprene, increasing mixing ratios during daytime are expected for light-triggered sources (Holzinger et al., 2002); temperaturetriggered sources would produce high concentrations in the evenings, when emissions are still strong but vertical mixing is suppressed by the developing nocturnal boundary layer. Biomass burning emissions of $\mathrm{CH}_{3} \mathrm{CN}$ coincide with substantial emissions of $\mathrm{CO}$ and a correlation between the two gases can be expected. However, no correlation between daytime levels of $\mathrm{CO}$ and acetonitrile (11:00-16:00 local time) was observed $\left(\mathrm{r}^{2}<0.05\right)$ if two short periods with significant correlation (Oct 7, 13:30-14:30; Oct 8, 13:30-14:30) were disregarded. In addition, if the high concentrations were due to biomass burning emissions we would rather expect more variability in the acetonitrile dataset. It seems very unlikely that constant biomass burning influence prevailed over the whole period of three weeks. An oceanic source is not triggered by air temperature or solar radiation. The transport of dissolved acetonitrile to the atmosphere is primarily driven by Henry's Law and by the mixing efficiency of 
both, the upmost layer of the ocean and the lowest layer of the atmosphere. Since the meteorological conditions were stable during the time of measurements, such a source explains much better the constant elevated mixing ratios during daytime hours when no nocturnal inversion layer is decoupling the ground from the boundary layer ( 09:00-18:00 in Fig. 2). We consider acetonitrile emission from the ocean to be the only reasonable assumption to explain both the high mixing ratios and the diurnal cycle of acetonitrile. This does not necessarily mean that the ocean is an additional source of acetonitrile. Perhaps more likely, the ocean acts as reservoir for acetonitrile: gas-phase acetonitrile is dissolved into seawater in regions were the ocean is cold. Dissolved acetonitrile might be released back into the atmosphere when the ocean warms up in tropical regions. The oceanic sink is probably much smaller than previously assumed if this speculation proves to be true and dissolved acetonitrile is not hydrolyzed or efficiently removed by micro organisms. However, a new non-biomass-burning source has to be assumed if acetonitrile is not stable enough to be transported over long distance in seawater. The general suitability of $\mathrm{CH}_{3} \mathrm{CN}$ as a biomass burning marker should be treated with care; even if there is no hydrolysis or other loss of dissolved acetonitrile.

Figure 3 shows average daytime acetonitrile levels (11:0016:00) versus average wind speeds. The graph includes all days with average daytime wind directions (11:00-16:00) deviating less than $50^{\circ}$ from the main wind direction (NE). Acetonitrile mixing ratios tended to be higher on days with higher wind speeds, i.e. when the air masses spent less time over the land. Since acetonitrile is effectively deposited into the savanna ecosystem such a linear relation is expected. In this way Fig. 3 supports both assumptions (i) that acetonitrile concentrations were higher over the Caribbean Sea and (ii) that dry deposition is a loss mechanism for this compound in savanna ecosystems.

Dry deposition over terrestrial ecosystems is a sink of acetonitrile that has not been accounted in global budgets so far. To our knowledge this is the first report of acetonitrile deposition over land. Unfortunately we do not have sufficient meteorological parameter to reliably calculate the deposition velocity. Assuming a completely isolated well mixed nocturnal inversion layer of $100 \mathrm{~m}$ (Octavio et al., 1987) a very rough estimate yields a deposition velocity $\left(\mathrm{v}_{d}\right)$ of $\sim 0.14 \mathrm{~cm} \mathrm{~s}^{-1}$ according to

$\mathrm{v}_{\mathrm{d}}=\left(\mathrm{d}_{42} \times \mathrm{h}\right) /\left(\mathrm{av}_{42} \times \mathrm{t}\right)$,

with $\mathrm{h}$ being the boundary layer height $(100 \mathrm{~m}), \mathrm{t}$ the duration of the night, $\mathrm{d}_{42}$ the average drop $(90 \mathrm{pmol} / \mathrm{mol})$, and $\mathrm{av}_{42}$ the mean concentration of acetonitrile during nights ( $165 \mathrm{pmol} / \mathrm{mol}$, see Fig. 2). During the 7 month long wet season over $2.7 \mathrm{mgN} / \mathrm{m}^{2}$ would be deposited, and if the value generally holds for tropical savannas $\left(6.6810^{6} \mathrm{~km}^{2}\right.$, Guenther et al., 1995) $0.053 \mathrm{Tg}$ acetonitrile would be deposited into savannas in this time period. Compared with the total estimated source of $\mathrm{CH}_{3} \mathrm{CN}$ of $\sim 0.4 \mathrm{Tg} \mathrm{N} / \mathrm{yr}$ (Singh et

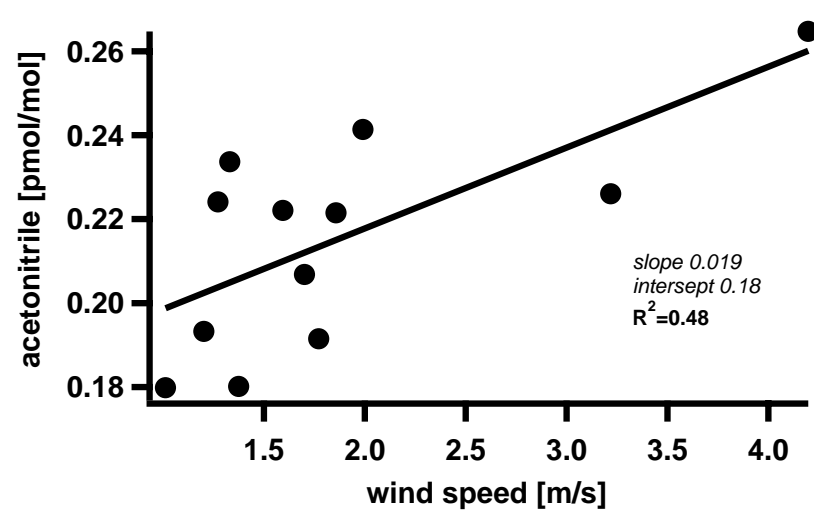

Fig. 3. Average daytime acetonitrile levels (11:00-16:00) versus average wind speeds.

al., 2003), the loss in savannas would be significant, but not major. However, if similar deposition velocities prevail also over other ecosystems, dry deposition over land might be a dominant sink for acetonitrile. Further measurements are needed to confirm or disprove this speculation.

\section{Conclusions}

High levels of acetonitrile were measured at the studied savanna region, in the absence of biomass burning emissions. The analysis of the data strongly suggests that acetonitrile is released from the Caribbean Sea. Recently, oceanic uptake of acetonitrile has been repeatedly reported. This study presents the first evidence that the ocean also acts as a source of acetonitrile. However, we speculate that rather than being produced acetonitrile is sequestered and transported in the ocean.

Also for the first time dry deposition of acetonitrile over a terrestrial ecosystem is reported in this article. If this happens in other ecosystems too, the roughly estimated deposition velocity implies the potential of dry deposition being a major sink of acetonitrile. This study provides new insights in the global cycle of acetonitrile. Acetonitrile is important as tracer for biomass burning; one of the largest global pollution sources. Further research is urgently needed. Improved understanding of the mechanisms controlling the atmospheric abundance of this gas would aid the quantification of global biomass burning emissions and help to improve the performance of global atmospheric chemistry models.

Acknowledgements. We thank the reviewers and Detlef Sprung for valuable comments and suggestions (see ACPD-homepage).We thank Elmar Uherek for preparing the acetonitrile standards. We thank the Carl-Zeiss-Stiftung for funding this project. The studies on biogeochemical cycles in tropical ecosystems received financial support from the Venezuelan National Science Council (CONICIT) through the Grant No G-98001124. We appreciate important logistic support and facilities at the Estación Biológica de los Llanos 
in Calabozo given by the Sociedad Venezolana de Ciencias Naturales. Rupert Holzinger thanks the Austrian "Fonds zur Förderung der wissenschaftlichen Forschung" for financial support (project no. J1743-PHY). Betina Kleiss thanks the Foundation Gran Mariscal de Ayacucho and the German Academic Exchange Service (DAAD) for financial support.

\section{References}

Arnold, F., Bohringer, H., and Henschen, G.: Composition Measurements of Stratospheric Positive-Ions, Geophys. Res. Lett., 5 (8), 653-656, 1978.

De Gouw, J. A., Warneke, C., Holzinger, R., Klüpfel, T., and Williams, J.: Inter-comparison Between Airborne Measurements of Methanol, Acetonitrile and Acetone Using Two Different Configured PTR-MS Instruments, submitted to Int. J. Mass Spectrom., 2004.

de Gouw, J. A., Warneke, C., Parrish, D. D., Holloway, J. S., Trainer, M. and Fehsenfeld, F. C.: Emission sources and ocean uptake of acetonitrile $\left(\mathrm{CH}_{3} \mathrm{CN}\right)$ in the atmosphere, J. Geophys. Res.-Atmos., 108(D11), 4329, doi:10.1029/2002JD002897, 2003.

Guenther, A., Hewitt, C. N., Erickson, D., Fall, R., Geron, C., Graedel, T., Harley, P., Klinger, L., Lerdau, M., McKay, W. A., Pierce, T., Scholes, B., Steinbrecher, R., Tallamraju, R., Taylor, J., and Zimmerman, P.: A Global-Model of Natural Volatile Organic-Compound Emissions, J. Geophys. Res.-Atmos., 100 (D5), 8873-8892, 1995.

Hamm, S., Hahn, J., Helas, G., and Warneck, P.: Acetonitrile in the Troposphere - Residence Time Due to Rainout and Uptake by the Ocean, Geophys. Res. Lett., 11 (12), 1207-1210, 1984.

Hamm, S. and Warneck, P.: The Interhemispheric Distribution and the Budget of Acetonitrile in the Troposphere, J. Geophys. Res.Atmos., 95 (D12), 20 593-20 606, 1990.

Holzinger, R., Kleiss, B., Donoso, L., and Sanhueza, E.: Aromatic hydrocarbons at urban, sub-urban, rural $\left(8^{\circ} 52^{\prime} \mathrm{N} ; 67^{\circ} 19^{\prime} \mathrm{W}\right)$ and remote sites in Venezuela, Atmos. Environ., 35 (29), 4917-4927, 2001.

Holzinger, R., Sanhueza, E., von Kuhlmann, R., Kleiss, B., Donoso, L., and Crutzen, P. J.: Diurnal cycles and seasonal variation of isoprene and its oxidation products in the tropical savanna atmosphere, Global Biogeochemical Cycles, 16(4), 2002.

Holzinger, R., Salisbury, G., Williams, J., Klüpfel, T., de Reus, M., Traub, M.,Crutzen, P. J., and Lelieveld, J.: Acetonitrile over the Eastern Mediterranean and its use for assessing the biomass burning contribution to the tropospheric burdens of $\mathrm{CO}$, acetone, methanol and PAN, Atmos. Chem. Phys., to be submitted, 2004.

Holzinger, R., Warneke, C., Hansel, A., Jordan, A., Lindinger, W., Scharffe, D. H., Schade, G., and Crutzen, P. J.: Biomass burning as a source of formaldehyde, acetaldehyde, methanol, acetone, acetonitrile, and hydrogen cyanide, Geophys. Res. Lett., 26 (8), 1161-1164, 1999.
Jost, C., Trentmann, J., Sprung, D., and Andreae, M. O.: Deposition of acetonitrile to the Atlantic Ocean off Namibia and Angola and its implications for the atmospheric budget of acetonitrile, Geophys. Res. Lett., 30 (16), 2003.

Karl, T., Hansel, A., Mark, T., Lindinger, W., and Hoffmann, D. Trace gas monitoring at the Mauna Loa Baseline observatory using proton-transfer reaction mass spectrometry, Int. J. Mass, 223 (1-3), 527-538, 2003.

Li, Q. B., Jacob, D. J., Yantosca, R. M., Heald, C. L., Singh, H. B., Koike, M., Zhao, Y. J., Sachse, G. W., and Streets, D. G.: A global three-dimensional model analysis of the atmospheric budgets of $\mathrm{HCN}$ and $\mathrm{CH}_{3} \mathrm{CN}$ : Constraints from aircraft and ground measurements, J. Geophys. Res.-Atmos., 108(D21), 8827, doi:10.1029/2002JD003075, 2003.

Lindinger, W., Hansel, A., and Jordan, A.: On-line monitoring of volatile organic compounds at pptv levels by means of protontransfer-reaction mass spectrometry (PTR-MS) - Medical applications, food control and environmental research, Int. J. Mass, 173 (3), 191-241, 1998.

Lobert, J. M., Scharffe, D. H., Hao, W. M., and Crutzen, P. J.: Importance of Biomass Burning in the Atmospheric Budgets of Nitrogen-Containing Gases, Nature, 346 (6284), 552-554, 1990.

Octavio, K. H., Arrocha, A., and Sanhueza, E.: Low nocturnal atmospheric dispersion capacity of the Venezuelan Savannah, Tellus, 39B, 286-292, 1987.

Sanhueza, E., Holzinger, R., Donoso, L., Santana, M., Fernández, E., and Romero, J.: Compuestos orgánicos volátiles en la atmósfera de La Gran Sabana. I: Concentraciones y química atmosférica, Interciencia, 26, 597-605, 2001.

Singh, H., Salas, L., Herlth, D., Kolyer, R., Czech, E., Viezee, W. Li, Q. B., Jacob, D., Blake, D., Sachse, G., Harward, C. N., Fuelberg, H., Kiley, C. M., Zhao, Y. J. and Kondo, Y.: In-situ measurements of $\mathrm{HCN}$ and $\mathrm{CH}_{3} \mathrm{CN}$ over the Oacific Ocean: Sources, Sinks, and budgets, J. Geophys. Res.-Atmos., in press, 2003.

Sprung, D., Jost, C., Reiner, T., Hansel, A., and Wisthaler, A.: Acetone and acetonitrile in the tropical Indian Ocean boundary layer and free troposphere: Aircraft-based intercomparison of APCIMS and PTR-MS measurements, J. Geophys. Res.-Atmos., 106 (D22), 28 511-28 527, 2001.

Warneke, C. and de Gouw, J. A.: Organic trace gas composition of the marine boundary layer over the northwest Indian Ocean in April 2000, Atmos. Environ., 35 (34), 5923-5933, 2001.

Warneke, C., de Gouw, J. A., Kuster, W. C., Goldan, P. D. and Fall, R.: Validation of atmospheric VOC measurements by proton-transfer- reaction mass spectrometry using a gaschromatographic preseparation method, Env. Sci. Tec., 37 (11), 2494-2501, 2003. 